\begin{tabular}{rr}
\hline Journal of Mathematics Science and Education \\
e-ISSN: $2623-2383.2018$, VOL. 1, NO. 1, 24-37 \\
OPENACCES & DOI: https://doi.org/10.31540/jmse.v1i1.162 \\
\hline
\end{tabular}

\title{
Learning Trajectory Pembelajaran Luas Permukaan Kubus dan
}

Balok

\section{Rani Refianti, Idul Adha}

STKIP PGRI Lubuklinggau, Indonesia

\begin{abstract}
ABSTRAK
Learning trajectory merupakan alur pemikiran siswa yang dihasilkan dari Hypothetical learning trajectory (HLT). Learning trajectory yang dihasilkan pada pembelajaran materi luas permukaan kubus dan balok dapat dijadikan dasar bagi guru dalam mengembangankan model, metode serta bahan ajar yang akan digunakan dalam pembelajaran. Metode penelitian yang digunakan adalah metode penelitian design research yang bertujuan mengembangkan local instruction theory melalui kerjasama antara peneliti dan guru dalam meningkatkan kualitas pembelajaran. Metode design research terdiri dari tiga tahapan yaitiu pre experimen, teaching experiment dan restropective analysis. Teknik pengumpulan data yang digunakan dalam penelitian ini adalah dokumentasi, wawancara dan observasi, dan tes. Data yang diperoleh selanjutnya dianalisis secara deskriptif. Analisis data hasil dokumentasi, wawancara, observasi, dan tes dilakukan secara kualitatif.
\end{abstract}

\section{Learning Trajectory of Learning the Surface Area of Cube and} Beams

ABSTRACT

Learning trajectory is the flow of students' thinking resulting from Hypothetical Learning Trajectory (HLT). Learning trajectory that is produced in learning material on the surface area of cubes and beams can be used as a basis for teachers in developing models, methods and teaching materials to be used in learning. The research method used in developing learning trajectories is a design research research method that aims to develop the local instruction theory through collaboration between researchers and teachers in improving the quality of learning. The design research method consists of three stages namely pre-experiment, teaching experiment and restropective analysis. Data collection techniques used in this study are documentation, interviews and observations, and tests. The data obtained were then analyzed descriptively. Analysis of data from documentation, interviews, observations, and tests were carried out qualitatively 
\begin{tabular}{rr}
\hline Journal of Mathematics Science and Education \\
e-ISSN: 2623-2383. 2018, VOL. 1, NO. 1, 24-37 \\
OPENACCES \\
DOI: https://doi.org/10.31540/jmse.v1i1.162 \\
\hline
\end{tabular}

KEYWORDS

Learning Trajectory, Luas Permukaan, Kubus, Balok Learning Trajectory, Surface Area, Cube, Beam
ARTICLE HISTORY

Received 24 November 2018

Revised 1 December 2018

Accepted 4 December 2018

CORRESPONDENCE Rani Refianti@ ranirefianti834@gmail.com

\section{PENDAHULUAN}

Kubus dan balok merupakan bangun dimensi tiga dengan sisi datar (bangun ruang sisi datar). Ada banyak benda atau bangunan yang dalam kehidupan sehari-hari yang merupakan refresentatif dari kubus dan balok. Namun kenyataannya siswa sering kali mendapatkan kesulitan dalam belajar belajar luas permukaan kubus dan balok. Seperti yang dikemukakan Kusumawati (2011) pada materi luas permukaan tugas yang diberikan oleh guru lebih banyak didominasi dengan pemberian soal untuk langsung menghitung luas permukaan, dimana pelaksanaan pembelajaran biasanya dimulai dengan penyajian materi,memberikan rumus dan contoh soal, setelah itu siswa diberi soal-soal latihan yang dikerjakan dengan menggunakan rumus yang sudah diberikan oleh guru. Siswa hanya perlu melihat rumus yang sudah diberikan dan mulai melakukan prosedur secara mekanis pada saat mengerjakan soal latihan. Kegiatan pembelajaran lebih banyak terpusat pada guru sebagai pemberi informasi mengenai materi yang dipelajari, kegiatan pembelajaran cenderung satu arah dimana guru memberikan instruksi mengenai rumus-rumus tanpa adanya kegiatan yang dapat memberikan pemahaman menyeluruh mengenai materi yang dipelajari. Hal serupa juga diungkapkan Fauzan (2002) salah satu permasalahan terbesar yang berkait dengan matematika modern ialah penyajian matematika sebagai produk jadi, siap pakai, abstrak dan diajarkan secara mekanistik: guru mendiktekan rumus dan prosedur ke siswa.

Selanjutnya berdasarkan hasil training Need Assessment yang dilaksanakan Pusat Pengembangan dan Pemberdayaan Pendidik dan Tenaga Kependidikan (PPPPTK) Matematika tahun 2007 dengan sampel sebanyak 268 pendidik sekolah Menengah Pertama (SMP) dari 15 propinsi menunjukkan bahwa sebanyak $43,7 \%$ guru masih memerlukan 


\begin{tabular}{rr}
\hline Journal of Mathematics Science and Education \\
e-ISSN: $2623-2383.2018$, VOL. 1, NO. $1,24-37$ \\
OPENACCES & DOI: https://doi.org/10.31540/jmse.v1i1.162 \\
\hline
\end{tabular}

pendalaman materi luas permukaan dan volume balok, kubus, prisma, serta limas, sebanyak 48,1\% guru masih memerlukan pendalaman materi sifatsifat kubus, balok, prisma, dan limas serta bagian-bagiannya, sebanyak $48,1 \%$ guru masih memerlukan pendalaman materi pembuatan jaringjaring kubus, balok, prisma, dan limas, dan sebanyak 45,9\% guru masih memerlukan pendalaman materi unsur-unsur tabung, kerucut, dan bola (Suwaji, 2008:1).

Dalam pembelajaran luas permukaan dibutuhkan suatu situasi konkret yang dapat menggambarkan aktivitas-aktivitas yang dapat memfasilitasi pengetahuan siswa, sehingga dapat lebih memahami konsep luas permukaan. Jika ditinjau dari permasalahan yang ada maka dibutuhkan suatu alternatif pembelajaran yang dapat memfasilitasi kebutuhan siswa terhadap pembelajaran matematika salah satunya dengan melakukan pendesainan terhadap learning trajectory luas permukaan kubus dan balok. Menurut Simon (1995) hypothetical learning trajectory terdiri dari 3 komponen yaitu tujuan pembelajaran, serangkaian tugas dan dugaan tentang cara berpikir dan belajar siswa. Kegiatan diawali dengan pendesainan terhadap hypothetical learning trajectory (HLT) dengan menggunakan pendekatan matemarika realistik indonesia (PMRI). Pendidikan Matematika Realistik Indonesia (PMRI) adalah sebuah pendekatan yang diadopsi dari Realistic Mathematics Education (RME), merupakan suatu pendekatan dalam pembelajaran matematika yang dikembangkan di Belanda sejak tahun 1970. RME berakar pada sebuah pandangan teoritis Freudenthal bahwa matematika sebagai aktivitas manusia (Gravemeijer, 1994). Hal ini menunjukan bahwa matematika hendaknya dirancang sesuai dengan kehidupan sehari-hari siswa.

Lebih lanjut, manfaat dan penggunaan Learning trajectory dalam pembelajaran matematikia, terutama pada materi luas permukaan kubus dan balok sangat membantu siswa dalam memperoleh pengalaman belajar yang lebih bermakna sehingga diharapkan mampu meningkatkan kemampuan pemahaman konsep matematika siswa khususnya pada materi luas permukaan kubus dan balok. Learning trajectory pada materi kubus dan balok dimulai dengan menggunakan kotak-kotak berbentuk kubus dan balok yang dapat dibongkar 


\begin{tabular}{rr}
\hline Journal of Mathematics Science and Education \\
e-ISSN: $2623-2383.2018$, VOL. 1, NO. $1,24-37$ \\
OPENACCES & DOI: https://doi.org/10.31540/jmse.v1i1.162 \\
\hline
\end{tabular}

pasang hingga membentuk jaring-jaring atau bangun dua dimensi. Selanjutnya siswa diberi panduan hingga dapat menemukan konsep luas permukaan kubus dan balok. Dengan adanya Learningtrajectory diharapkan pembelajaran di matematika dapat lebih maksimal baik dari segi peserta didik ataupun dari segi pendidik.

\section{METODE}

Penelitian ini menggunakan metode peneitian design research. Metode design research adalah suatu metode penelitian yang bertujuan untuk mengembangkan local instruction theory melalui kerjasama antara peneliti dan guru dalam meningkatkan kualitas pembelajaran (Graveimeijer \& Van Eerde, 2009). Menurut Gravemeijer dan Cobb (2006) metode design research meliputi 3 tahapan yaitiu 1) pre experimen; 2) teachingexperiment; 3) restropective analysis. Ketiga tahapan tersebut dapat dijabarkan sebagai berikut

\section{1) Pre experimen.}

Pada tahap pre experimen dilakukan pengkajian literatur mengenai materi luas permukaan kubus dan balok, standar kompetensi (SK) dan kompetensi dasar (KD) dan kurikulum yang digunakan di sekolah. Selanjutnya peneliti melakukan diskusi dengan guru mata pelajaran mengenai kondisi siswa, diskusi secara langsung dengan siswa, telaah bahan ajar yang digunakan di sekolah, serta melakukan pendesainan Hypotenical Learning Trajectory (HLT). Hypothetical Learning Trajectory merupakan suatu hipotesis atau dugaan bagaimana pemikiran dan pemahaman siswa berkembang dalam suatu aktivitas pembelajaran. HLT yang telah dirancang oleh peneliti selanjutnya di diskusi dengan guru mata pelajaran. Dari hasil diskusi diperoleh masukan yang menjadi dasar perbaikan HLT prototipe 1. Adapun masukan yang diperoleh yakni merubah benda konkrit yang digunakan dalam desain awal yang mulanya mengamati benda-benda yang terdapat di lingkungan sekolah dengan bentuk kubus dan balok diganti dengan menyiapkan kotak-kotak yang berbentuk kubus dan balok, hal ini bertujuan agar suasana kelas tetap tertib. HLT prototipe 1 ini kemudian diujicobakan pada kelompok kecil, hasil dari 


\begin{tabular}{rr}
\hline Journal of Mathematics Science and Education \\
e-ISSN: $2623-2383.2018$, VOL. 1, NO. 1, 24-37 \\
OPENACCES \\
DOI: https://doi.org/10.31540/jmse.v1i1.162 \\
\hline
\end{tabular}

kelompok kecil direvisi guna perbaikan HLT hasil revisi yakni HLT prototipe 2 kemudian digunakan pada kelompok besar.

\section{2) Teaching experiment.}

Teaching experiment terdiri dari uji coba kelompok kecil dan uji coba kelompok besar. Uji coba kelompok kecil dilakukan untuk mengujicobakan HLT yang telah dirancang. Uji coba pada kelompok kecil dilakukan terhadap enam orang siswa yang tidak berasal dari kelas sebenarnya, keenam siswa yang dipilih memiliki kemampuan yang berbeda-beda terdiri dari dua orang siswa berkemampuan tinggi, dua orang siswa berkemampuan sedang dan dua orang siswa berkemampuan rendah. Uji coba terhadap kelompok kecil bertujuan untuk menguji hypothetical learning trajectory (HLT) awal guna mengetahui bagian mana saja yang perlu direvisi ulang. Hasil dari HLT yang telah direvisi kemudian diuji cobakan pada kelas besar yakni kelas yang menjadi subjek penelitian. Pada tahapan ini hypothetical learning trajectory (HLT) merupakan pedoman utama apa yang menjadi fokus dalam proses pembelajaran. Selama proses uji coba, setiap aktivitas direkam dengan menggunakan dokumentasi foto dan video. Pada tahapan ini peneliti berperan sebagai observer, sedangkan guru pelajaran matematika berperan sebagai guru model. Beberapa orang siswa dipilih untuk diwawancarai selama proses berlangsung guna memperoleh informasi yang mendukung LIT (local instructional theory ) setelah itu hasil pekerjaan siswa dikumpulkan untuk dilakukan analisis, data yang dikumpulkan pada tahapan ini bertujuan untuk menjawaban pertanyaan penelitian.

\section{3) Restropective analysis}

Pada tahap Restrospective Analysis data yang diperoleh pada tahap teaching experiment dan hasil dari analisisnya tersebut digunakan untuk merancang kegiatan pada pembelajaran berikutnya.

Secara keseluruhan tahapan-tahapan dilalui dalam penelitian ini, dapat digambarkan dalam bentuk diagram di bawah ini :

https://ojs.stkippgri-lubuklinggau.ac.id/index.php/JMSE 


\begin{tabular}{cr}
\hline Journal of Mathematics Science and Education \\
e-ISSN: 2623-2383. 2018, VOL. 1, NO. 1, 24 - 37 \\
OPENACCES
\end{tabular}$\quad$\begin{tabular}{l} 
DOI: https://doi.org/10.31540/jmse.v1i1.162 \\
\hline
\end{tabular}

\section{Gambar 1 Tahapan-tahapan Penelitian}

\begin{tabular}{|c|c|}
\hline $\begin{array}{l}\text { Pre experimen. } \\
\text { 1. Pengkajian literatur } \\
\text { 2. Pengkajian standar kompetensi } \\
\text { (SK) dan kompetensi dasar } \\
\text { (KD) dan kurikulum yang } \\
\text { digunakan di sekolah. } \\
\text { 3. Diskusi dengan guru mata } \\
\text { pelajaran dan siswa secara } \\
\text { langsung } \\
\text { 4. Pendesainan Hypotenical } \\
\text { Learning Trajectory (HLT). }\end{array}$ & $\begin{array}{l}\text { Teachingexperiment. } \\
\text { 1. Uji coba HLT pada kelompok } \\
\text { kecil } \\
\text { 2. Wawancara, observasi dan } \\
\text { diskusi mengenai apa yang } \\
\text { difikirkan siswa dalam upaya } \\
\text { penyesuaian terhadap } \\
\text { learning trajectory }\end{array}$ \\
\hline $\begin{array}{l}\text { Restrop } \\
\text { Analisis data yang di } \\
\text { experiment dan hasi } \\
\text { digunakan untuk } 1 \\
\text { pembelajaran berikutr }\end{array}$ & $\begin{array}{l}\text { analysis } \\
\text { h pada tahap teaching } \\
\text { analisisnya tersebut } \\
\text { ang kegiatan pada }\end{array}$ \\
\hline
\end{tabular}

HASIL dan PEMBAHASAN

Tahap awal yang dilakukan pada penelitian ini yakni merancang learning trajectory atau lintasan belajar berdasarkan Local Instructional Theory (LIT) luas permukaan bangun ruang sisi datar yang dikemukakan Keshway (2013) yakni untuk memperoleh luas permukaan kita harus dapat menghitung luas setiap sisi dan menjumlahkannya. Selanjutnya Local Instructional Theory (LIT) dikembangkan dikembangkan dalam bentuk Hypothetical Learning Trajectory (HLT) Ada tiga tahap yang dilalui dalam penelitian ini yaitiu 1) pre experimen; 2) teachingexperiment; 3) restropective analysis. Adapun uraian aktivitas ketiga tahapan tersebut adalah sebagai berikut :

\section{Pre experiment}

Tahap ini diawali dengan melakukan pengkajian literatur terhadap bahan ajar https://ojs.stkippgri-lubuklinggau.ac.id/index.php/JMSE 
apa saja yang digunakan di sekolah, metode yang digunakan guru dalam menyampaikan informasi, serta pengkajian terhadap kurikulum yang digunakan disekolah guna penyesuain terhadap kompetensi dasar dan standar kompetensi yang akan digunakan. Berdasarkan hasil pengkajian dan diskusi dengan guru mata pelajaran matematika diketahui bahwa di sekolah guru menggunakan buku paket matematika kelas VIII yang diperoleh dari penerbit, semua siswa dalam satu kelas memiliki buku paket tersebut dan menggunakannya sebagai sumber belajar. Selain itu soal tugas dan pekerjaan rumah (PR) juga diambil dari buku tersebut. Kurikulum yang di gunakan sekolah pada saat itu yakni KTSP, pada kurikulum KTSP materi luas permukaan kubus dan balok ada pada materi kelas dua semester dua. Poin yang terdapat pada standar kompetensi (SK) yakni memahami sifat-sifat kubus, balok, prisma,limas dan bagian-bagiannya serta menentukan ukurannya. Sedangkan kompetensi dasar (KD) yang diharapkan adalah membuat jaring-jaring kubus, balok,prisma dan limas serta menghitung luas permukaan dan volume kubus,balok, prisma dan limas. Dalam hal ini materi dibahasi hanya pada pokok bahasan kubus dan balok dengan pertimbangan agar pembelajaran di kelas dapat lebih maksimal dan siswa dapat lebih paham konsep. Selain diskusi dengan guru mata pelajaran matematika, peneliti juga melakukan diskusi langsung dengan beberapa siswa guna mengetahui minat mereka mengenai pembelajaran matematika, serta proses pembelajaran seperti apa yang mereka harapkan. Berdasarkan hasil diskusi tersebut diperoleh informasi bahwa sebagian dari mereka menyenangi matematika dan menginginkan pembelajaran matematika yang menyenangkan, tdak hanya rumus dan contoh soal.

Berdarkan hasil diskusi dengan siswa dan guru mata pelajaran matematika serta pengkajian literatur dan kurikum yang digunakan, maka dirancanglah suatu Hypothetical Learning Trajectory (HLT) atau dugaan pemikiran dengan tujuan agar tujuan pembelajaran dapat tercapai dan siswa lebih paham konsep yang disampaikan serta pembelajaran di kelas menjadi lebih bermakna dan menyenangkan. Peneliti juga merancang LKS siswa yang disesuaikam dengan HLT yang memuat serangkaian kegiatan siswa mengenai luas permukaan kubus dan balok. 


\begin{tabular}{rr}
\hline Journal of Mathematics Science and Education \\
e-ISSN: $2623-2383.2018$, VOL. 1, NO. $1,24-37$ \\
OPENACCES & DOI: https://doi.org/10.31540/jmse.v1i1.162 \\
\hline
\end{tabular}

Menurut Kershway (2013) luas permukaan adalah penutup dari bangun tiga dimensi. Untuk mengukur luas permukaan suatu bangun datar seperti kubus dan balok dapat menggunakan kotak berbentuk kubus dan kotak berbentuk balok yakni dengan cara membongkar kotak tersebut hingga membentuk jaring-jaring atau bangun dua dimensi. Teori tersebut dijadikan landasan dalam menyusun Hypothetical Learning Trajectory (HLT) dan pemyusunan LKS. Secara keseluruan HLT yang telah dirancang dapat disajikan pada bagan berikut ini :

Gambar 2 (HLT)

HYPOTHETICAL LEARNING TRAJECTORY (HLT) LUAS PERMUKAAN KUBUS DAN BALOK

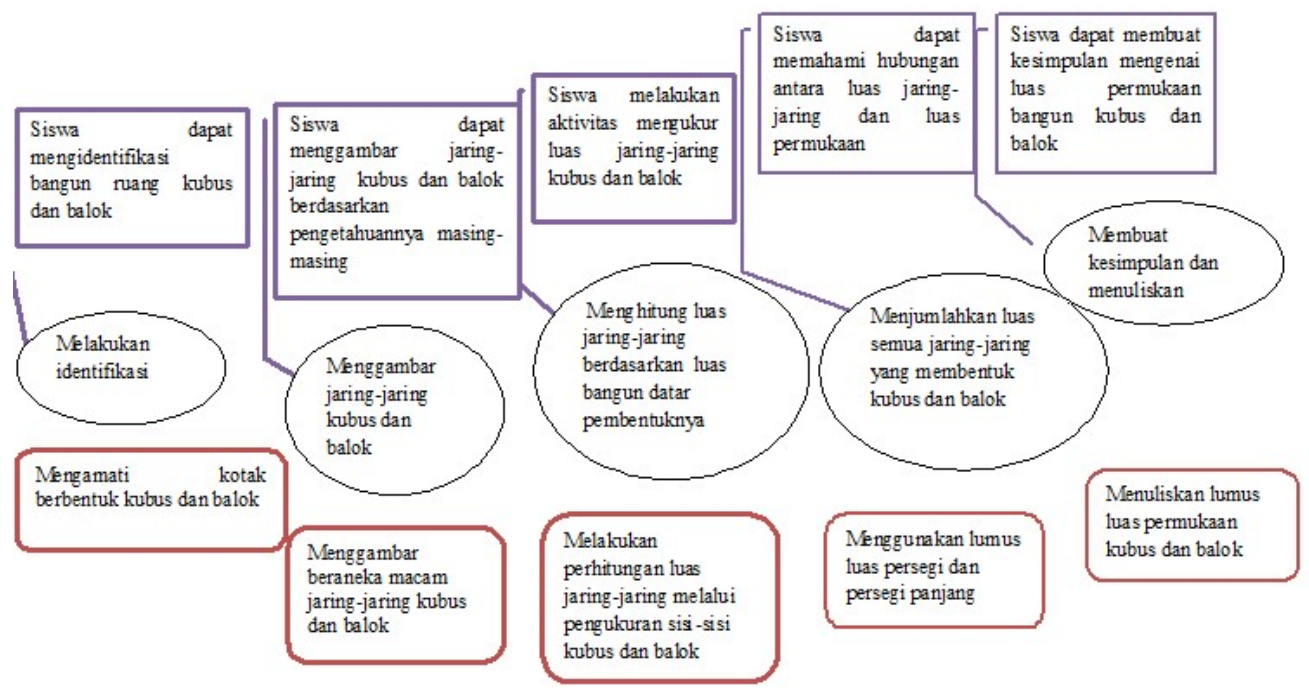

\section{2) Teaching experiment}

Pembelajaran dilaksanakan dalam dua fase yaitu fase 1 kelompok kecil danfase 2 kelompok besar. Pada kelompok kecil pembelajaran diberikan enam orang siswa dengan kemampuan yang berbeda-beda. Keenam siswa tersebut berasar dari kelas yang berbeda dengan kelompok besar. HLT awal atau prototipe 1 yang telah diperoleh diujicobakan pada kelompok kecil untuk melihat kemampuan siswa, Berdasarkan uji coba pada kelompok kecil HLT selanjutnya direvisi untuk kemudian diuji cobakan pada kelompok besar. Berdasarkanhasil aktivitas pada kelompok kecil, terlihat siswa dapat memahami konsep luas 


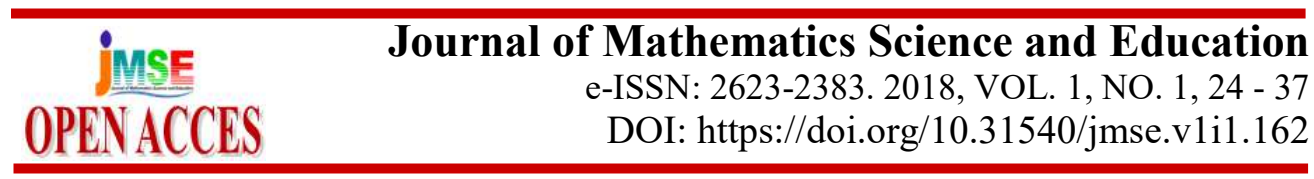

permukaan kubus, hal tersebut terlihat dari cara siswa menuliskan jawaban ketika diberikan suatu permasalahan, dimana siswa dapat memahami bahwa luas permukaan sama dengan luas jaring-jaring, hanya saja pada aktivitas kelompok kecil siswa masih belum dapat menuliskan rumus luas permukaan secara lengkap hingga tahap formal. Setelah peneliti menganalisi jawaban siswa dan meminta siswa mengemukakan mengenai hasil pekerjaannya diperoleh informasi bahwa pemahaman siswa akan konsep luas permukaan sudah baik, hal ini dapat dilihat dari jawaban siswa seperti gambar 3, hanya saja untuk mengaikan konsep luas permukaan hingga sampai pada matematika formal siswa masih mengalami kesulitan.

\section{Gambar 3 Hasil pekerjaan siswa saat uji coba kelompok kecil}
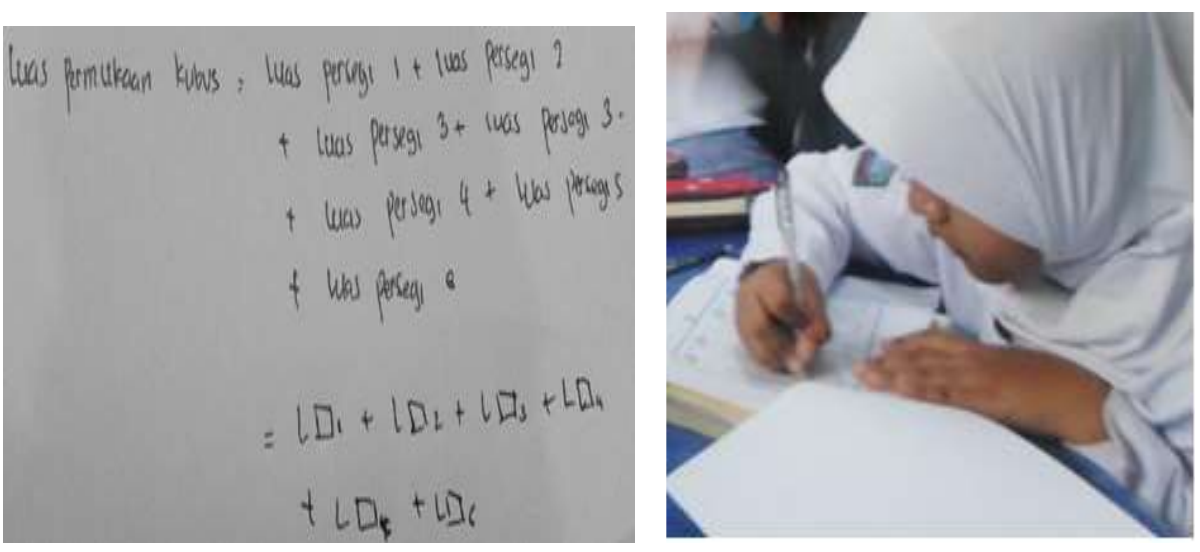

Selanjutnya berdasarkan hasil aktivitas pada kelompok kecil dilakukan perbaikan terhadap Hypothetical Learning Trajectory (HLT) sehingga menghasilkan prototipe 2 yang selanjutnya diuji cobakan pada kelompok besar dan menghasilkan teori lokal.Di bawah ini Learning Trajectory yang telah mengalami revisi.

\section{Gambar 4 Learning trajectory luas permukaan kubus dan balok}

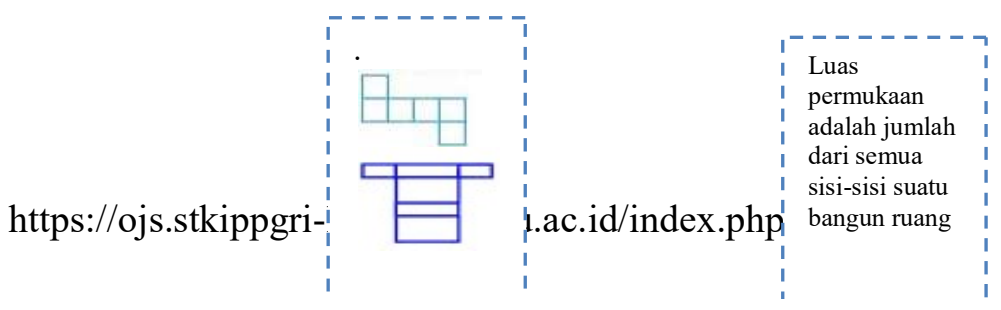




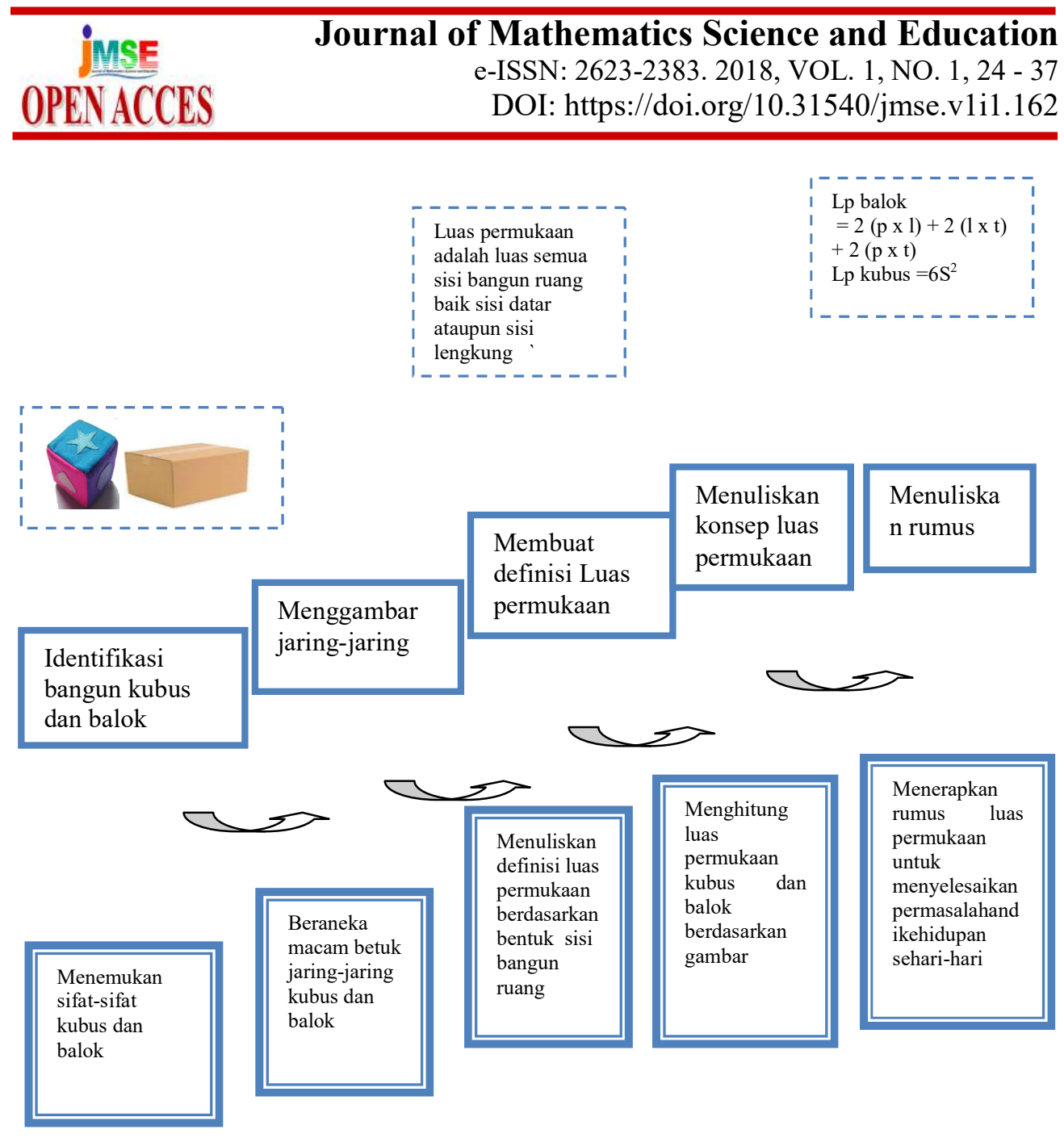

Learning trajectory yang telah direvisi selanjutnya di ujicobakan pada kelas besar, pada aktivitas pertama siswa pembelajaran dimulai dengan melakukan identifikasi terhadap bangun ruang kubus dan balok, dimana dalam hal ini siswa diminta menyebutkan benda-benda apa saja yang berbentuk kubus dan balok yang paling sering mereka temui selanjunya Pada kegiatan ini dilekatkan suatu permasalah untuk membangun dasar pemahaman tentang konsep luas permukaan kubus dan balok, mulanya terlebih dahulu siswa diminta untuk menuliskan hasil dari identifikasi yang telah dilakukan dan menuliskan hasilnya, selanjutnya siswa diminta untuk menggambar jaring-jaring kubus dan balok berdasarkan pengetahuannya masing-masing. Dari jaring-jaring ini siswa diarahkan pada aktivitas memahami bahwa jaring-jaring merupakan bangun dua dimensi yang memiliki kaitan dengann bangun tiga dimensi. Selanjutnya siswa diarahkan untuk 


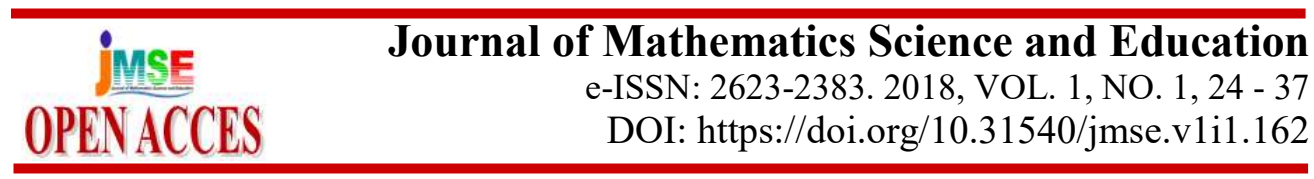

sampai ke level formal yakni menuliskan rumus luas permukaan kubus dan balok. Pada aktivitas kedua, peneliti menyajika permasalah dalam bentuk yang sedikit berbeda guna memantapkan pemahaman siswa melalui aktivitas-aktivitas pada lembar kegiatan yang telah dirancang. Berikut contoh jawaban siswa dari aktivitas yang diberikan :

\section{Gambar 5 Hasil Aktivitas siswa}

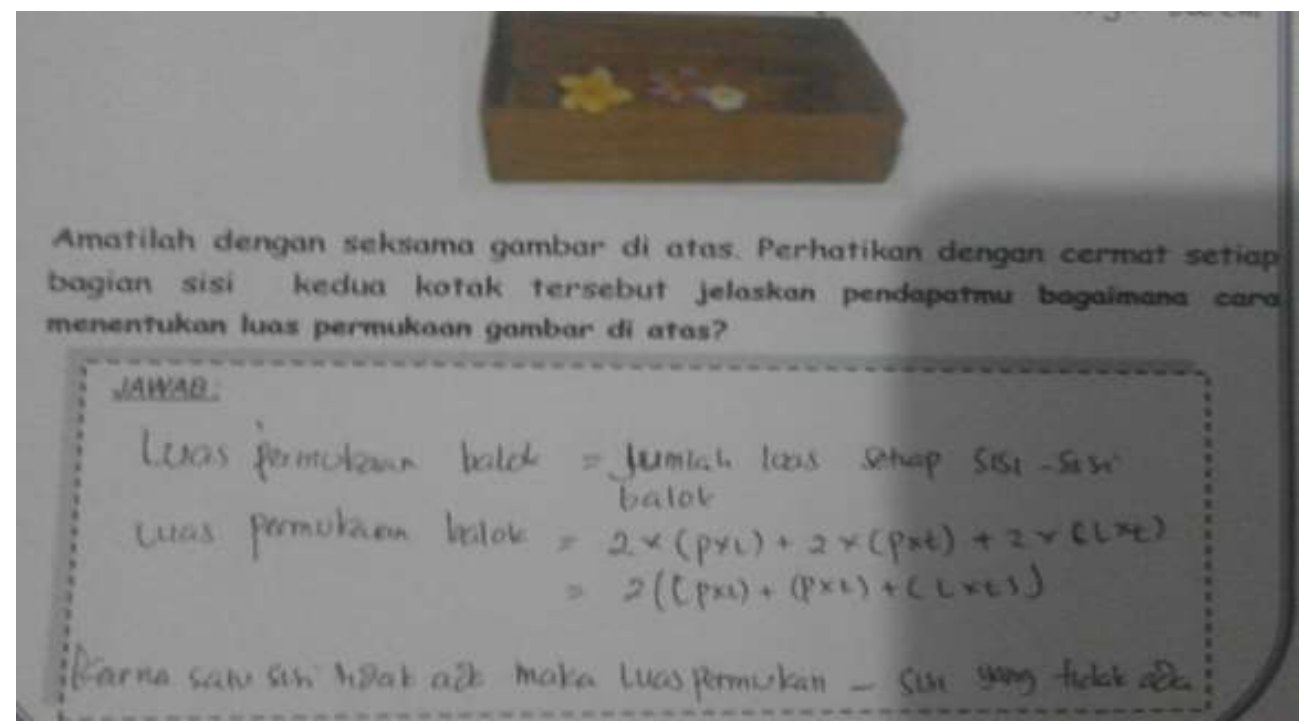

Berdasarakan gambar di atas terlihat bahwa siswa telah memami konsep luas permukaan balok, hal ini terlihat dari cara siswa menuliskan jawaban pada lembar yang disediakan. Siswa menuliskan bahwa luas permukaan balok merupakan hasil dari penjumlahan sisi-sisi balok, sehingga untuk menentukan luas permukaan suatu balok cukup dengan memahami bentuk dari sisi-sisi balok tersebut, dilanjutkan dengan menentuka luas pada tiap sisi-sisi dan kemudian menjumlahkan kesemua luas tersebut maka diperolelah luas permukaan. Karena pada gambar terdapat satu sisi -sisi balok tidak lengkap hanya terdiri dari lima sisi maka sisiwa menuliskan bahwa luas permukaan balok tersebut hendaklah dikurangi luas sisi yang tidak ada hal ini tampak seperti pada gambar di atas

\section{Gambar 6 hasil aktivitas}

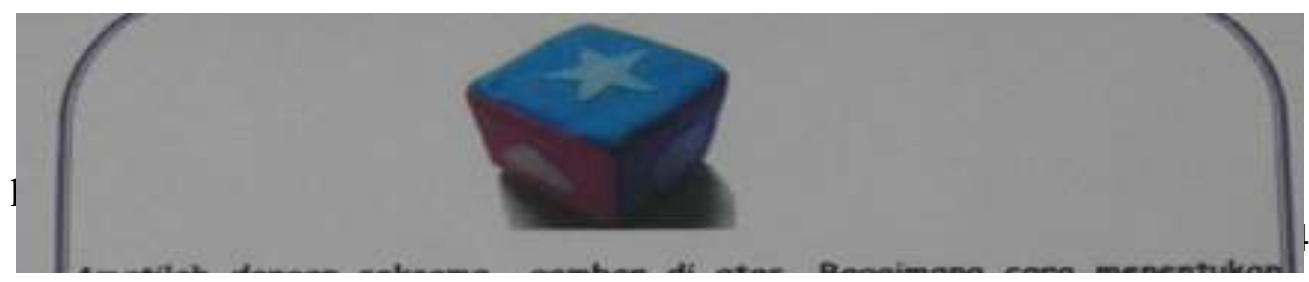




\begin{tabular}{cr}
\hline JuSE & $\begin{array}{r}\text { Journal of Mathematics Science and Education } \\
\text { e-ISSN: 2623-2383. 2018, VOL. 1, NO. 1, 24 - 37 } \\
\text { OPENACCES }\end{array}$ \\
\hline
\end{tabular}

Berdasarkan aktivitas pertama terlihat bahwa siswa melakukan perhitungan terhadap luas permukaan dengan mengaplikasikan konsep luas permukaan dimana siswa menuliskan bahwa luas permukaan kubus merupakan jumlah luas sisi-sisi kubus dan selanjutnya sisiwa mengaplikasikan konsep tersebut untuk menghitung luas permukaan kubus.

\section{Gambar 7hasil aktivitas siswa}

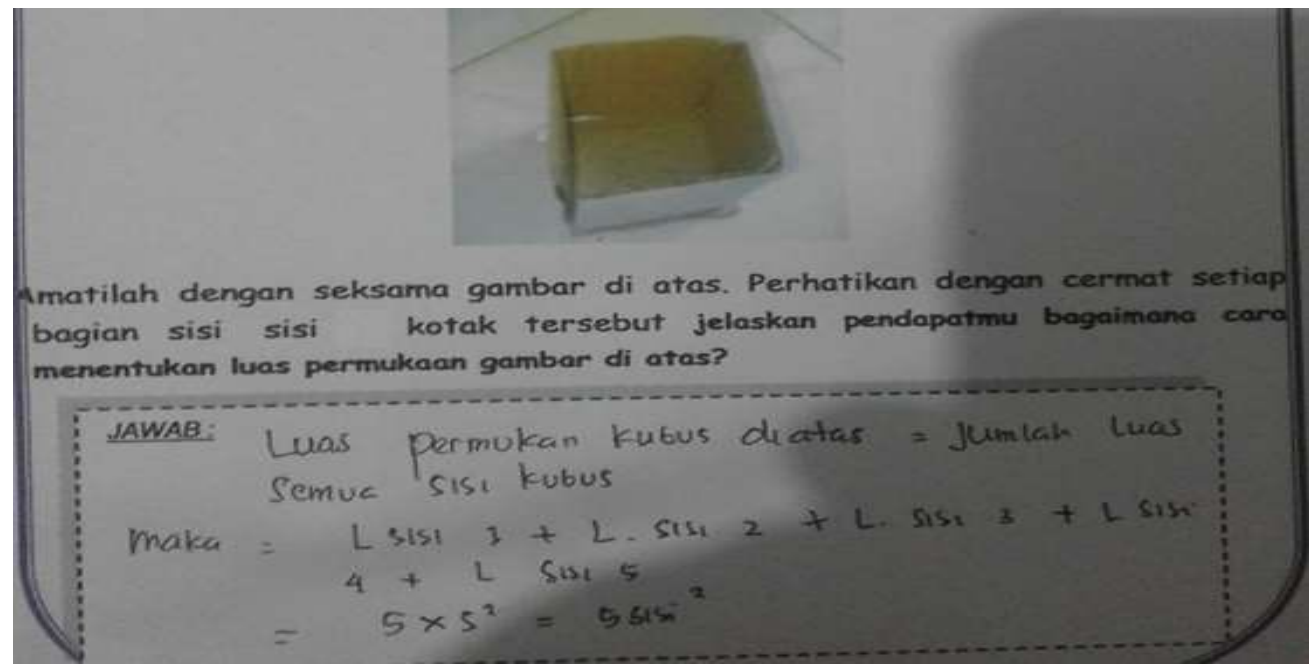

Berdasarkan permasalahn pada aktivitas kedua, terlihat seperti pada gambar 7 peneliti meminta siswa menentukan luas permukaan kubus jika salah satu sisi tidak diketahui, dengan tujuan memantau sejauh mana pemahaman siswa mengenai konsep luas permukaan kubus. Terlihar seperti pada gambar 7 di atas siswa telah memahami konsep luas permukaan kubus, dimana siswa tidak 
menghitung bagian sisi yang tidak ada. Untuk luas permukaan kubus di atas siswa hanya menuliskan $5 \mathrm{~s}^{2}$. Sebab hanya terdapat lima sisi pada kubus tersebut.

Berdasarkan hasil pekerjaan yang telah dilakukan siswa, terlihat bahwa terlihat bahwa learning trajectory atau lintasan belajar yang di dirancang dapat membantu siswa dalam memahami materi luas permukaan kubus dan balok, hal ini dapat dilihat dari cara siswa menuliskan konsep luas permukaan pada lembar aktivitas.

\section{KESIMPULAN}

Berdasarkan hasil dan pembahasan yang telah diuraikan, dapat disimpulkan bahwa penggunaan benda-benda konkret seperti kotak berbentuk kubus dan balok dapat membantu siswa memahami konsep luas permukaan kubus dan balok melalui aktivitas-aktivitas seperti mengidentifikasi bangun ruang kubus dan balok, menggambar jaring-jaring, menuliskan definisi luas permukaan hingga sampai pada level formal yakni menuliskan rumus luas permukaan kubus dan balok sehingga dari aktivitas-aktivitas yang telah dilakukan menghasilkan suatu learning trajectory atau lintasan belajar yang dapat membantu siswa dalam memahami konsep luas permukaan kubus dan balok. Lintasan belajar yang dihasilkan dalam penelitian ini adalah lintasan-lintasan belajar yang dilalui siswa mulai dari menidentifikasi bangun ruang kubus dan balok, menggambarkan jaring-jaring kubus dan balok, menyebutkan bangun datar apa saja yang terdapat pada kubus dan balok dan menemukan rumus luas permukaan kubus dan balok

Learning trajectory atau lintasan belajar yang dihasilkan dari penelitian ini berakar dari Local Intrucsional Theory (LIT) yang di susun peneliti berdasarkan pendapat ahli bahwa untuk memperoleh luas permukaan kita harus dapat menghitung luas setiap sisi dan menjumlahkannya. Selanjutnya LIT ini dikembangkan hingga menghasilkan suatu learning trajectory atau lintasan belajar pada materi luas permukaan bangun ruang sisi datar yakni kubus dan balok

\section{DAFTAR PUSTAKA}




\begin{tabular}{rr}
\hline Journal of Mathematics Science and Education \\
e-ISSN: $2623-2383.2018$, VOL. 1, NO. $1,24-37$ \\
OPENACCES & DOI: https://doi.org/10.31540/jmse.v1i1.162 \\
\hline
\end{tabular}

Fauzan, A. (2002). Applying realistic mathematics education in teachin geometry inIndonesian primary schools. Doctoral dissertation. Enschede: Universityof Twente. Tersedia: http://doc.utwente.nl/58707/1/thesis_Fauzan.pdf. Diakses pada tanggal 8 desember 2013

Gravemeijer, K. (1994). Developing Realistic Mathematics Education. Utrecht: Freudenthal Institute.

Gravemeijer, Koeno \& Paul Coob. (2006). Deisgn reseacrh form a Learning Design Perspective. In : jan Van den Akker, Koeneo Graveimejr, Susan Mckeny fan Nienke Nieveen. Educational Desaign Research . London: Routdledge.

Kershway, J. (2013). CK-12 Middle School Math Grade 7. Tersedia online : http://www.ck12.org/geometry/Surface-Area-of-TriangularPrisms/lesson/Surface-Area-of-Triangular-Prisms/

Kusumawati,E.(2011). Pembelajaran Kubus dan Balok Menurut Standar Pengajaran NCTM Dengan Setting Kooperatif. Edumatica 1(1) : 33-43.

Simon, M. A. (1995). Reconstructing Mathematics Pedagogy from a Constructivist Perspective.Journal for Research in Mathematics Education, 26(2), 114-145. Tersedia dalam http://www.math.ntnu.Edu.tw.

Suwaji, U. T. (2008). Permasalahan Pembelajaran Geometri Ruang SMP dan Alternatif Pemecahan. Yogyakarta: PPPPTK Matematika. Tersedia: http://p4tkmatematika.org/fasilitasi/18-Permasalahan-pembelajaramgeometri-ruang-smp.pdf 